\title{
A espacialidade do modo de vida - Análise morfológica de comunidades rurais e tradicionais na região do Baixo Tocantins (PA)
}

\section{The spatiality of a way of life - A morphological analysis of rural and traditional communities in the Lower Tocantins region (PA)}

Kamila Diniz Oliveira - Doutoranda em Arquitetura e Urbanismo no Programa de Pós Graduação em Arquitetura e Urbanismo (PPGAU) da Universidade Federal do Pará (UFPA).E-mail: kamiladinizoliveira@gmail.com

Ana Clándia Duarte Cardoso - Doutora em Arquitetura pela Oxford Brookes University, UK. Professora da Universidade Federal do Pará (UFPA). E-mail: aclaudiacardoso@gmail.com

\section{Resumo}

Desde os anos 1960, as políticas dirigidas para a Amazônia perseguem um "desenvolvimento", pela transformação do meio natural e social existente e pela difusão da urbanização extensiva. $O$ artigo investiga a expressão espacial do modo de vida em assentamentos urbano-rurais, localizados na região do Baixo Tocantins. A caracterização do modo de vida de quatro comunidades, que mantêm suas atividades vinculadas ao ritmo da natureza, permitiu o entendimento da apropriação e do uso dos espaços. O adensamento populacional, a instalação de infraestruturas, e a assimilação de valores citadinos explicam as transformações espaciais observadas nos assentamentos. As principais formas de reorganização espacial observadas foram: a transferência das áreas de residências para o centro da comunidade e a subdivisão das áreas de trabalho. Concluiu-se que a identificação dos processos e as transformações espaciais são recursos fundamentais para a formulação de políticas públicas de base territorial destinadas à Amazônia.

\section{Palavras-chave}

Morfologia. Modo de vida. Assentamento Tradicional. Baixo Tocantins.

\begin{abstract}
Since the 1960s, policies directed towards the Amazon have pursued "development" through the transformation of the existing natural and social environment and the spread of extensive urbanization. The article investigates the spatial expression of the way of life in urban-rural settlements located in the Lower Tocantins region. The characterization of the way of life of four communities that maintain their activities linked to the rhythm of nature allowed the understanding of the appropriation and use of spaces. Population densification, the installation of infrastructure and the assimilation of city values explain the spatial transformations observed in the settlements. The main forms of spatial reorganization observed were: the transfer of residential areas to the community centre and the subdivision of work areas. It was concluded that the identification of spatial processes and transformations are fundamental resources for the formulation of territorially-based public policies for the Amazon.
\end{abstract}

\section{Keywords}

Morphology. Lifestyle. Traditional Settlement. Baixo Tocantins. 


\section{INTRODUÇÃO}

A ocupação humana nativa na Amazônia, herdeira do período précolonial, segue um padrão de dispersão no território; pequenos conglomerados se localizam estrategicamente às margens de rios, pequenas estradas ou em áreas apropriadas para plantio (OLIVEIRA NEVES, 2009). A trajetória de evolução dos assentamentos que originaram as cidades foi marcada por surtos econômicos de produtos voltados para exportação. Esta prática foi estabelecida durante a colonização portuguesa e intensificada pela concepção de desenvolvimento ${ }^{1}$ do governo militar (BECKER, 2013).

Neste período, foi estabelecido um processo de exploração colonialista na Amazônia, que a posicionou como região periférica e voltada para fora, cuja produção era dirigida para exportação e que ignorava os habitantes locais (VIANA; SIMÕES; BASTOS, 2019). As políticas federais baseadas nessa estratégia promoveram a exploração de recursos naturais, a geração de energia e a produção agropecuária, desencadeando uma completa transformação do meio natural e social. A prioridade dada à provisão de infraestrutura logística para a produção negligenciou o modo como os entrelaçamentos históricos entre as dimensões urbana e rural dão suporte à vida das pessoas na região.

Tais transformações na estrutura produtiva repercutiram no conjunto da vida social. A fronteira agromineral, o processo da colonização e assentamento dirigido pelo Estado e o processo de conversão de uso por iniciativa privada foram decisivos para a transformação da dinâmica social de áreas rurais, por promoverem a penetração de frentes migratórias. Segundo Hébette e Moreira (1996, p. 385), a população que migrou para a região trouxe características próprias e sua cultura e, ao mesmo tempo em que ela modificou e transformou o território, ela o violentou e fecundou; além disso, as manifestações nas áreas rurais impactaram a floresta e os territórios de populações indígenas e tradicionais, gerando novas dinâmicas sociais que foram acompanhadas pela constituição de uma fronteira urbana, manifesta na criação de novas cidades e na periferização das existentes.

\footnotetext{
De acordo com Monte-Mór (2015), a concepção hegemônica de desenvolvimento advém de um pacto internacional entre as classes dirigentes, implicando a difusão das racionalidades, dos modos de organização e das formas de reprodução das relações sociais de produção dos velhos aos novos espaços dominados pelo capitalismo. Nesse sentido, o desenvolvimento implica não só transformações estruturais na economia e na sociedade, mas uma aposta na industrialização como caminho para a modernização estrutural das instituições sociopolíticas e culturais. Todavia, o uso do autoritarismo impediu que soluções de base endógena emergissem em resposta aos problemas específicos da sociedade, bloqueando os processos sociais, suprimindo a criatividade e frustrando o que neste texto se entende por genuíno desenvolvimento.
} 
Essa transformação aconteceu em paralelo à superação das escalas urbanas, regionais, nacionais e globais, pelo fenômeno da urbanização. Brenner (2013) reúne autores que advogam que há uma urbanização planetária em curso, bem como alertam sobre o impacto das demandas do capitalismo sobre territórios não metropolitanos, tais quais aqueles ocupados por populações locais, que vivem fora do mercado e contam com modos de vida e tradições não pautados pela industrialização (GOMES et al., 2017). Há décadas, Monte-Mór (1994) argumenta que há uma urbanização extensiva² em curso na Amazônia, ligada à reestruturação produtiva do campo a partir do "tecido urbano" gerado pela logística para produção, articulador de usos industriais no espaço antes visto como rural, e da extensão das manchas urbanas em gradientes periurbanos.

Contra este pano de fundo, este artigo investigou padrões espaciais em quatro comunidades rurais localizadas na região do Baixo Tocantins, selecionadas dentre 18 comunidades visitadas inicialmente, por terem sido capazes de resistir e se adaptar às transformações promovidas desde a implantação de rodovias. Estas comunidades distam de 10 a $20 \mathrm{~km}$ da cidade de Mocajuba, duas delas também estão a menos de $25 \mathrm{~km}$ da cidade de Cametá (ao Norte) e outras duas estão a menos de $20 \mathrm{~km}$ da cidade de Baião (ao Sul).

Dentre as quatro comunidades, duas são ligadas ao Projeto de Assentamento Agroextrativista Ilha Grande, uma é remanescente de quilombo, e a quarta foi implantada na estrada por famílias camponesas sem identidade tradicional. As quatro comunidades contam com algum impacto da proximidade das cidades, e também dos desdobramentos da urbanização extensiva na região. O objetivo da pesquisa foi caracterizar a produção desse tipo de espaço de transição urbanorural contemporâneo, por meio do modo de vida para visibilizar os conflitos e subsidiar políticas públicas apropriadas, visto que a carência de registros favorece a implantação de sistemas construtivos, espacialidades e soluções de infraestrutura importadas das periferias das cidades, que tendem a alterar as condições de vida nas comunidades (PINHO; OLIVEIRA; CARDOSO, 2021).

Este foco é justificado, por um lado, pelo modo como a combinação de ações dos setores público e privado tem fomentado novas espacialidades, ampliando a vulnerabilidade das comunidades na escala local, face ao apagamento da memória dos saberes da floresta e ao desvanecimento dos arranjos espaciais

2 O conceito de urbanização extensiva refere-se ao fenômeno de extrapolação da cidade pelo tecido urbano, que se torna capaz de sobrepor no território as condições de produção industrial capitalista (mercado de trabalho, infraestrutura, energia, serviços sociais, comunicação e transportes, reprodução coletiva da força de trabalho, etc.) virtualmente a todo o espaço social, fortalecendo e enfatizando a superação da dicotomia urbano-rural, dada a articulação criada entre concentrações urbanas e microssistemas urbano-rurais, com ampliação de possibilidades econômicas e sociais (MONTE-MÓR, 2015). 
amazônicos (CARDOSO; CÂNDIDO; MELO, 2018; MONTE-MÓR, 2015; PONTES, 2015).

A região em tela apresenta uma gama de formas de existência coletiva, de diferentes povos e grupos sociais, que sobrevivem dos recursos da natureza. Nesse sentido, parte-se do fato de que a identidade das populações tradicionais ${ }^{3}$ está intrinsecamente relacionada com o rio, a terra e a floresta, e ao conhecimento empírico do bioma e de suas variações ecológicas. Outrossim, aponta-se que o acesso aos recursos naturais para o exercício de atividades produtivas não é pautado somente pela composição do grupo étnico, dos grupos de parentes, da família, do povoado ou da aldeia, mas também pelo grau de coesão e solidariedade alcançado quando são enfrentadas situações de extrema adversidade e conflito, quando as redes de relações sociais são politicamente reforçadas (ALMEIDA, 2004). Nesse aspecto, os problemas enfrentados pelas quatro comunidades se aproximam.

Por outro lado, as práticas de conservação dos solos, água, fauna e flora em sistemas de produção, desenvolvidas há séculos nesta região, advêm do conhecimento dos elementos naturais acumulados por estas comunidades. Assim, a compreensão de seus padrões espaciais é importante para a viabilidade da reprodução humana baseada no manejo dos recursos naturais, para a segurança alimentar e também para a integridade da natureza, reconhecida como principal fonte de recursos para a economia da região.

\section{ESTRATÉGIA DE REGISTRO DA ESPACIALIDADE DO MODO DE VIDA}

As configurações espaciais construídas pelas civilizações refletem o seu modo de viver e a forma como se relacionam com o ambiente que habitam, seja ele natural ou construído. Os arranjos espaciais das quatro comunidades estudadas retratam o espaço das práticas cotidianas da várzea e da terra firme na região do Baixo Tocantins, a partir de uma perspectiva interdisciplinar, integrando conceitos e ferramentas da Morfologia Urbana, Geografia, Antropologia e Sociologia, para resgatar a formação e produção do espaço de assentamentos, e fomentar o diálogo entre as concepções de cultura e espaço, com os conceitos de apropriação, comportamento socioespacial e percepção espacial.

3 Grupos culturalmente diferenciados e que se reconhecem como tais, que possuem formas próprias de organização social, que ocupam e usam territórios e recursos naturais como condição para sua reprodução cultural, social, religiosa, ancestral e econômica, utilizando conhecimentos, inovações e práticas gerados e transmitidos pela tradição. Esses grupos ocupam e usam, de forma permanente ou temporária, territórios tradicionais e recursos naturais como condição para sua reprodução cultural, social, religiosa, ancestral e econômica (BRASIL, 2007). 
A pesquisa procurou articular categorias da Antropologia e da Sociologia (análise do modo de vida) às ferramentas de análise da Escola de Italiana Morfologia Urbana, utilizando o método de ampliação de escala ${ }^{4}$ (COSTA; GIMMLER NETTO, 2015) para caracterizar um modo de vida e revelar sua expressão espacial, mesmo que a expressão "modo de vida" seja polissêmica e de difícil conceituação (DURKHEIM, 2010; LEFEBVRE, 1999; WEBER, 1991).

Para Guerra (1993), a análise dos modos de vida deve relacionar o objetivo e o subjetivo na percepção do real, considerando: (1) o sistema e os atores sociais; (2) a história; e (3) o cotidiano. Esses aspectos devem ser articulados de modo a combinar a força da estrutura socioeconômica com a possibilidade de ação dos indivíduos e o nível da vida cotidiana, combinando aspectos econômicos, políticos e culturais, bem como redes de poder estabelecidas nas articulações entre as diferentes esferas sociais. De acordo com a autora, o estudo do modo de vida encontra-se frente a um dilema: se por um lado, a análise da vida cotidiana assumiria a forma de uma mediação horizontal, por outro lado, a análise dos modos de vida submete-se a lógica da reprodução da força de trabalho.

Guerra (1993) explica ainda que as pesquisas mais recentes sobre o modo de vida focam em dois aspectos: a análise da relação entre as diferentes práticas cotidianas - trabalho, vida familiar, consumo, lazer etc. - e, nas relações que o conjunto dessas práticas cotidianas estabelece com as relações sociais mais gerais. Assim, os estudos ligados aos aspectos da vida cotidiana deveriam preocuparse com o grau de consciência dos atores sobre a condução dos seus destinos, individuais e coletivos.

O registro dos padrões espaciais e das formas de uso e apropriação dos espaços foi feito por meio de uma viagem de campo exploratória realizada em agosto de 2018, que visitou dezoito comunidades em quinze dias e permitiu a seleção dos quatro casos, como já mencionado na introdução. Em junho de 2019 e outubro de 2019 ocorreram as vivências nas quatro comunidades, que tiveram duração média de 10 dias, quando foram feitas observações de campo, registros fotográficos e entrevistas. As vivências permitiram compreender o modo de vida das comunidades e como esse modela a espacialidade do assentamento.

\footnotetext{
Segundo Costa e Gimmler Netto (2015), o método de ampliação de escala da escola de morfologia urbana italiana parte da análise de um elemento isolado (ex.: um pequeno assentamento) e amplia gradativamente a escala, até que abranja a concepção da ocupação de todo o território. Sua aplicação foi fundamental para a compreensão morfológica dos assentamentos das comunidades estudadas. As edificações encontradas nos assentamentos e seus usos foram assumidos como os elementos básicos para a classificação espacial das comunidades (OLIVEIRA, 2020), visto que se trata de espaço coletivo, onde não há separações análogas às delimitações urbanas, de parcelas de apropriação privada, a exemplo de lotes, muros, cercas, grades e outros.
} 
A observação foi calibrada pela visão de tridimensionalidade do espaço contida na obra de Lefebvre (2006), que coloca a dimensão espacial no mesmo patamar da historicidade e da sociabilidade. Isso porque, para o autor, a realidade e os processos sociais contêm uma dimensão espacial intrínseca e, por isso, não é possível entender o espaço como produto, dissociado do processo que o gerou (LEFEBVRE, 2006).

A tridimensionalidade do espaço social de Lefebvre (2006) é composta por três espacialidades - o percebido, o concebido e o vivido - sem nenhum privilégio inerente a priori. Tais dimensões dos espaços foram consideradas para compreensão do assentamento de populações de várzea e terra firme: o espaço vivido vem da prática cotidiana do habitante, o espaço concebido pelo registro oficial e histórico disponível e o espaço percebido foi gerado pela análise morfológica.

O entendimento do modo de vida das quatro comunidades auxiliou na assimilação do espaço vivido. Nesse movimento, observou-se como os habitantes percebem e apropriam-se do espaço, como constroem e organizam as edificações, como são as estratégias de controle de cada território, como organizam as formas de produção, onde e como são os espaços de lazer, além de compreender os eventuais problemas e conflitos das comunidades.

O espaço concebido ajudou no esclarecimento da formação dos assentamentos tradicionais na região, a partir dos processos históricos e econômicos. O espaço percebido, abordado por meio da análise morfológica, agregou as informações dos outros espaços, principalmente do espaço vivido, para justificar os arranjos espaciais encontrados. Nessa perspectiva, a apropriação de sítios de várzea e terra firme representa um mecanismo social de adaptação às características peculiares desse ambiente natural e social.

\section{FORMAÇÃO DA REGIÃO DO BAIXO TOCANTINS}

A Região do Baixo Tocantins ficou conhecida pela antiga regionalização feita pela Secretaria Estadual de Integração Regional, já extinta hoje. Trata-se de onze municípios que compõem a região, conforme exposto na Figura 1. A população total da região é de 740.045 habitantes, dos quais 52,80\%, ou 390.748, vivem na área rural (IBGE, 2010).

A historiografia oficial não menciona como era a ocupação da região antes de 1500, embora um número crescente de pesquisas arqueológicas destaque a sofisticação e volume das civilizações que povoaram a região (LOPES, 2017). O relato oficial se reporta à intenção frustrada de estabelecimento do sistema de plantation na região, bem como à ação das ordens religiosas na estruturação 
da coleta de produtos da floresta (chamadas "drogas do sertão"), e subsequente dominação e destribalização dos indígenas, com destaque para o cultivo do cacau, cana-de-açúcar, mandioca e pequena pecuária (MDA, 2011).

Figura 1 - Mapa de localização da região de Integração do Tocantins

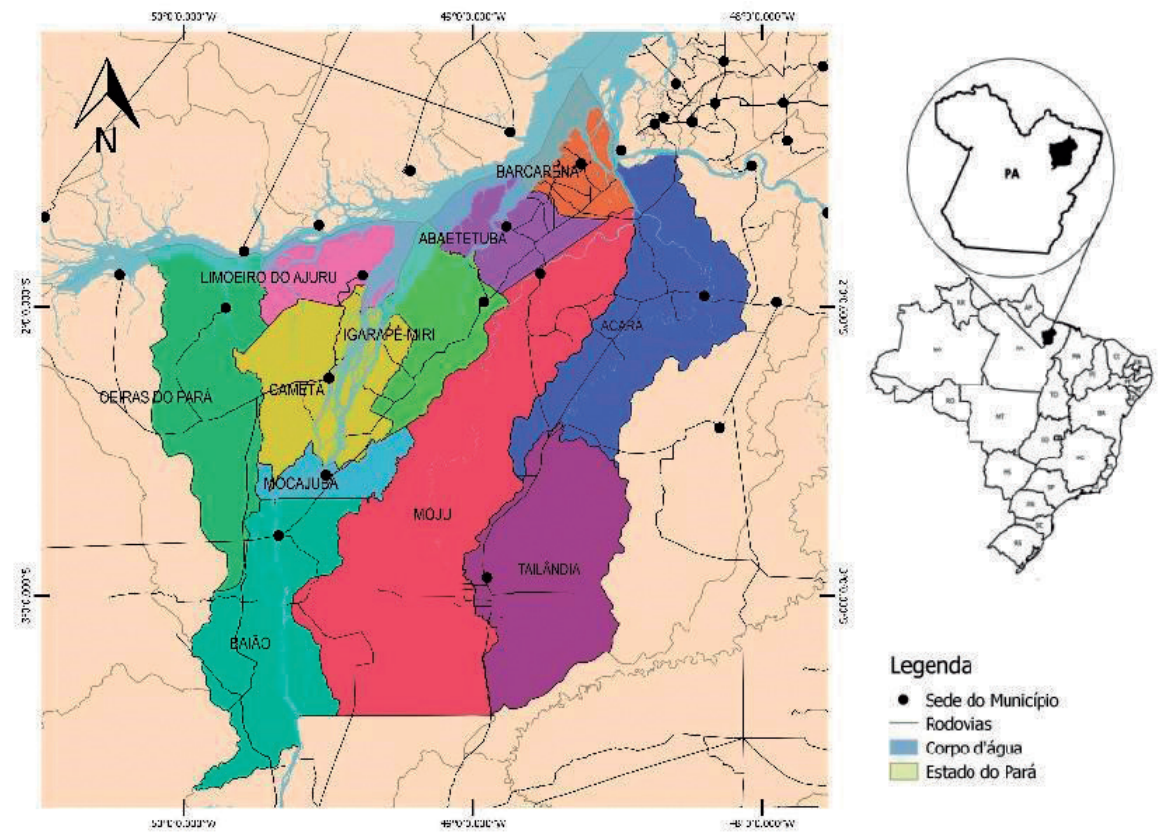

Elaboração das autoras, 2021.

No século XVIII, após a difusão da fé católica entre os indígenas e a expulsão dos missionários, a Gestão do Marquês de Pombal transformou as aldeias missionárias em freguesias e vilas, povoando a calha dos rios, porém as diversas tentativas de escravização dos indígenas e a importação de africanos escravos resultaram na formação de comunidades de indígenas e negros fugidos em áreas embrenhadas na floresta, de difícil acesso - os quilombos - que tiveram protagonismo na ocupação da área de estudo (MALHEIRO; TRINDADE JÚNIOR, 2009).

Até então, os rios estruturavam o território do Baixo Tocantins e viabilizavam o transporte de mercadorias e pessoas, gerando um padrão de ocupação denominado por Porto-Gonçalves (2005) de 'rio-várzea-floresta'. O mesmo autor também destaca o estabelecimento de um novo padrão de ocupação a partir da década de 1970, o da 'estrada-terra firme-subsolo', após o melhoramento de rodovias federais e pavimentação das estaduais como a PA-150, PA-151, além da Transcametá (PA-156), associadas às intervenções do projeto Grande Carajás, como a construção da UHE Tucuruí. 
Os governos militares consolidaram políticas que atrelaram as ideias de integrar, ocupar e desenvolver o território, por meio da industrialização, à doutrina de segurança nacional (BRITO, 2001). Desde então, a política desenvolvimentista provocou alterações significativas na região e estabeleceu o padrão rodoviário como vetor de expansão urbana. Novos bairros surgiram ao longo das estradas e a transição cidade-campo passou a ser definida pela instalação de redes técnicas (viária, de telecomunicações, elétrica), alterando as formas de ocupação espacial e as tipologias de assentamentos humanos, com impactos socioambientais relevantes a partir do final da década de 1990 (CARDOSO; LIMA, 2006).

A geração de energia permitiu a produção de alumina no complexo Albrás-Alunorte e o abastecimento das grandes cidades do país. Contudo, após a construção da barragem da UHE Tucuruí, houve mudança no regime da várzea à jusante, deslocamento de populações indígenas, redução de pescado, contaminação dos rios, erosão de margens e elevação dos casos de malária (MALHEIRO; TRINDADE JÚNIOR, 2009).

Apesar da situação de intensa urbanização da população, a presença de populações tradicionais em espaço rural se manteve forte, vinculada ao extrativismo de coleta, produção agrícola (agricultura familiar) e pesca artesanal, para quem a natureza viva tem sentido econômico, e o rio tem um sentido multifuncional (circulação fluvial, fonte de alimento, identidade sociocultural). Entre 1960 e 1990, esse campesinato amazônico contou com o apoio das Comunidades Eclesiais de Base (CEB) na formação do Sindicato de Trabalhadores Rurais (STR), associações e cooperativas que fomentaram a criação de cantinas comunitárias e a assistência técnica às áreas de cultivo localizadas ao longo das rodovias PA-151 e PA-156, que se constituíram em eixo de expansão urbana, articulando comunidades, vilas e povoados próximos ou nas margens das estradas (COSTA, 2006).

Tais coexistências geraram trajetórias de uso e ocupação da terra concorrentes, como a desenvolvimentista, que estabelece o "tecido urbano estendido" estruturado a partir da logística, e a tradicional, explicitada na Figura 2 que apresenta os projetos de assentamentos, as unidades de conservação, as terras indígenas e as áreas quilombolas criadas na região para atender às demandas das populações tradicionais, já que a luta pela terra e em defesa de seus territórios ficou forte na década de 1980, sob o protagonismo político da aliança dos povos da floresta, em especial, indígenas e quilombolas. Desde então, esse movimento se capilariza, gera políticas que associam a proteção ambiental, reconhecimento identitário e designação territorial, visibilizando a sociobiodiversidade brasileira, por intermédio de vários instrumentos legais para defesa de seus direitos, como as demarcações de unidade de conservação, de projetos de assentamento 
agroextrativista, de terra indígena e outros, e que hoje resiste, apesar das mudanças políticas ocorridas em 2016.

Figura 2 - Mapa de localização dos projetos de assentamento, unidades de conservação, terras indígenas e áreas quilombolas na região de Integração do Tocantins

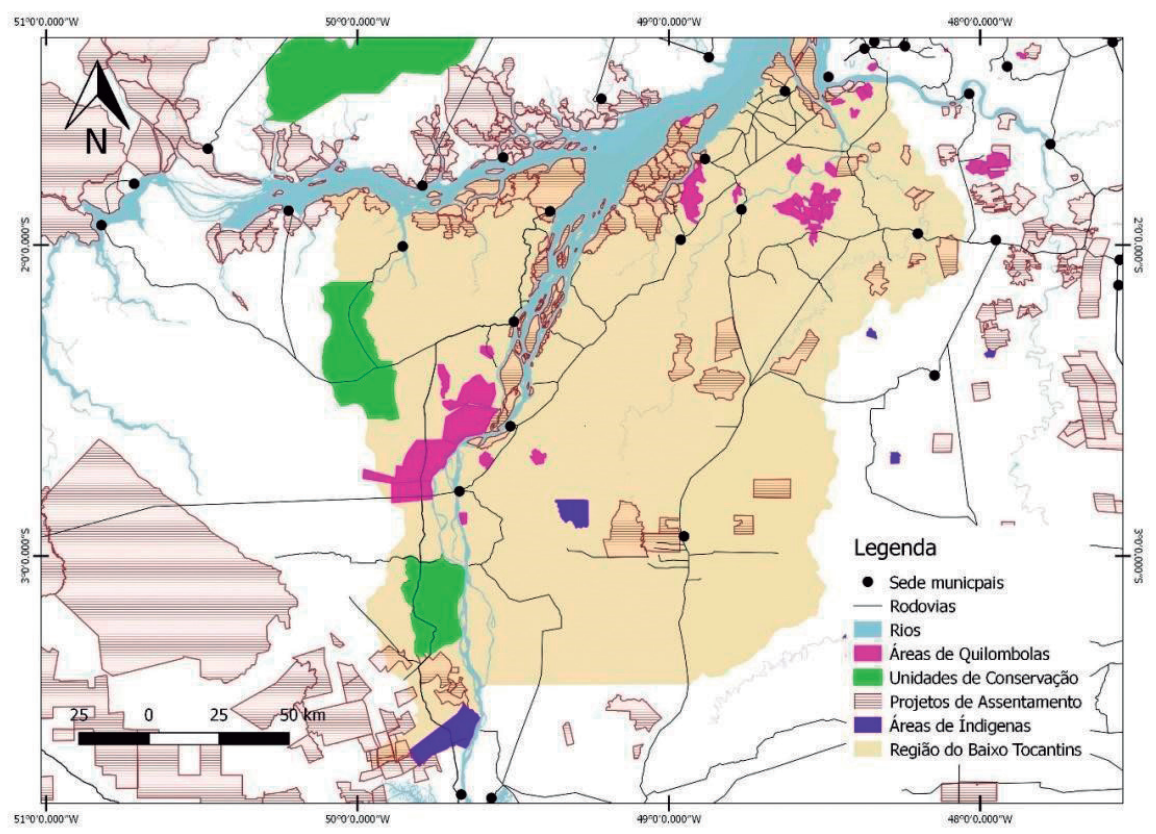

Elaboração das autoras, 2021.

De acordo com os dados do IBGE (2016), são 130 projetos de assentamento: dois PE (Projeto de Assentamento Estadual), 26 PA (Projeto de Assentamento Federal) e 102 PAE (Projeto de Assentamento Agroextrativista). Ao todo, são mais de 30.000 mil famílias assentadas na região, que também contém duas Reservas Extrativistas (RESEX) - Arióca Pruanã e Ipaú Anilzinho. Ademais, a região apresenta 27 áreas quilombolas, e os contingentes mais expressivos estão localizados em comunidades rurais que se situam às margens de rios e igarapés, com economia baseada na pequena agricultura familiar de natureza extrativista. Esse mosaico de projetos e unidades socioambientais foi um avanço na regularização fundiária da região, na medida em que reduziu os conflitos pelo uso e pela posse da terra e a insegurança, especialmente dos extrativistas e agricultores familiares, em relação aos produtores (exportadores) de pimenta do reino, baseados em terra firme e na beira das estradas. 
Após a queda da cultura da pimenta-do-reino, devido a fatores, tais como o desgaste do solo, queda do valor do produto no mercado, falta de incentivos de créditos e de assistência técnica (MALHEIRO; TRINDADE JÚNIOR, 2009), a vocação agroextrativista da região continuou desfavorecida porque as bases de dados oficiais passaram a destacar os dados da exportação mineral a partir de Barcarena. O extrativismo passou a ser contabilizado somente quando o açaí, palmeira nativa da região estudada e base da alimentação local, tornou-se uma commodity demandada globalmente como fruto, em forma de polpa, como sorvete, mix, energético, refrigerante, cosmético, etc. (CORRÊEA, 2016). Em 2014, o Baixo Tocantins produziu um quarto do açaí exportado pelo Brasil e atraiu para a várzea indústrias de beneficiamento de açaí, e mudanças na forma de produção do fruto que estão provocando algumas transformações no modo de vida daqueles grupos que dependem do fruto para sobreviver.

Contudo, de acordo com as entrevistas realizadas, a expansão do açaí no mercado externo permitiu um aumento do consumo de bens industrializados pelas famílias (televisores, aparelhos de som, refrigeradores), mas não promoveram melhorias coletivas significativas nas comunidades ribeirinhas que têm o cultivo do açaí como uma de suas principais atividades. As famílias extrativistas ou vendem o açaí para os atravessadores, cooperativas e geleiras in natura a preços baixos, sem nenhuma agregação de valor, ou se dirigem às cidades, sede dos municípios e distritos para realizar a venda nas feiras, como sempre aconteceu (IPEA, 2011).

Mas essa produção familiar acontece em paralelo a projetos de manejo florestal dos açaizais e ao avanço do monocultivo da palmeira que têm provocado alterações profundas na paisagem do Baixo Tocantins. Por isso a mobilização social em defesa da produção tradicional se tornou umas das principais preocupações difundidas pelos assentados e representantes de instituições de pesquisa, na medida em que o monocultivo promove a substituição de outras espécies vegetais que historicamente têm sido fundamentais para o manejo da biodiversidade na região pelo açaí plantado.

\section{CARACTERIZAÇÃO DO MODO DE VIDA E ANÁLISE MORFOLÓGICA DOS ASSENTAMENTOS ESTUDADOS}

Os arranjos espaciais são expressão do modo de viver e da forma como as pessoas se relacionam com o ambiente que habitam, seja ele natural ou construído. Os arranjos espaciais apresentados neste artigo retratam o espaço das práticas cotidianas de quatro comunidades, três delas tradicionais, localizadas na várzea e na terra firme na região do Baixo Tocantins. 
A caracterização do modo de vida foi feita a partir das informações obtidas por meio de entrevistas detalhadas realizadas com uma família que mantém as atividades de produção ligadas à produção agrícola e extrativista em cada comunidade, somadas às observações de campo no espaço de moradia e de trabalho dessas comunidades. As comunidades pesquisadas foram Nossa das Graças de Furtados, Mutuacá de Baixo, São José de Icatu e Cantanzal (que não é tradicional). As duas primeiras comunidades são ribeirinhas e estão localizadas no Projeto Agroextrativista Ilha Grande, já as duas últimas estão localizadas em terra firme, como pouca conexão com o rio. As comunidades estudadas dependem da proximidade das cidades, pois é lá que vendem os excedentes da produção, nas feiras, e onde utilizam alguns serviços (bancos, hospitais e outros).

Figura 3 - Mapa de localização das comunidades visitadas e as distâncias dos centros urbanos mais próximos

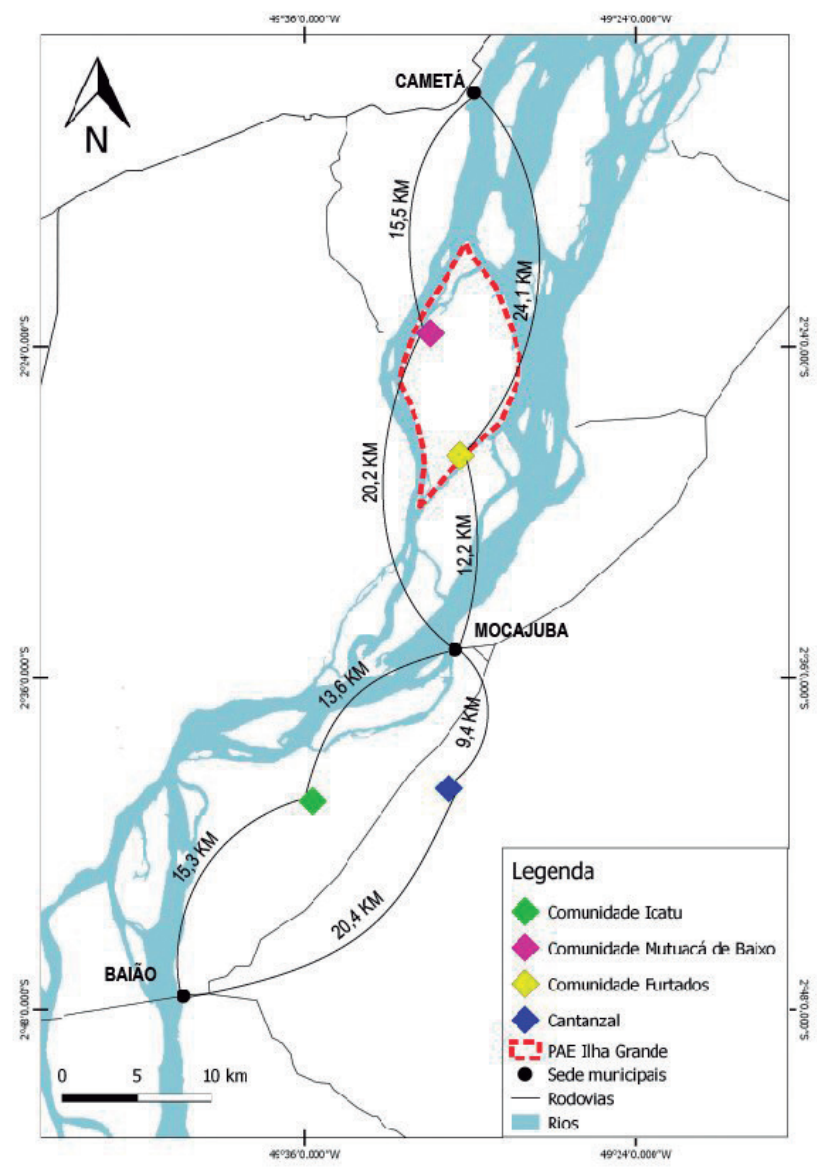

Elaboração das autoras, 2021. 
A Figura 3, acima, apresenta a localização das comunidades e as distâncias dos centros urbanos mais próximos. As delimitações do espaço apropriado pelas comunidades representadas no mapa estão baseadas nas informações dos moradores das comunidades. Observou-se que o espaço de moradia abarca múltiplas formas de apropriação, pois nas áreas de praça ou terreiro as atividades de trabalho não são separadas dos rituais religiosos, de festividades ou outras manifestações da vida. Isso favorece a sociabilidade grupal e define a intensidade de integração das relações, seja no âmbito do núcleo familiar, ou seja, no de parentesco dentro da comunidade. A cultura da convivialidade difere das práticas observadas na cidade, indica concepções específicas, que foram construídas e acumuladas em épocas e territórios diversos (CASTRO, 1998).

Além dos espaços de moradia, também foi possível observar que, para a produção, as comunidades tradicionais ocupam tanto as áreas de terra firme quanto as várzeas localizadas na região das ilhas. Na terra firme, predomina a agricultura familiar, com cultivo da mandioca para a produção de farinha, enquanto nas ilhas o extrativismo do açaí desponta como a principal produção. Essas comunidades têm suas vidas cotidianas condicionadas pelas oscilações das marés. Canoas, voadeiras e embarcações de pequeno porte (chamados localmente de "po-po-pôs") constituem a principal forma de transporte e canal das relações comerciais entre os agricultores, pescadores e extrativistas com o meio urbano (MALHEIRO; TRINDADE JÚNIOR, 2009).

Como em outros contextos camponeses, os movimentos confessionais, sindicais e sociais historicamente têm participação na criação e articulação de lideranças nas comunidades e no fortalecimento do senso de coletividade (MENEZES NETO, 2007). Tal articulação permitiu que as comunidades passassem a buscar melhores condições de moradia, a reivindicar assistência à saúde e educação, e a organizar mutirões para improvisar a instalação de rede de distribuição de energia elétrica, e realizar ligações clandestinas de energia. Essas demandas indicam uma expectativa de usufruto de serviços que, antes, eram restritos às cidades, ainda que em outro patamar de oferta, pelas comunidades em todo o território municipal. Também indica que a ampliação da capacidade de organização social entre as comunidades é um fenômeno reverso do processo de urbanização extensiva disseminado por ação dos setores público e privado, por meio da implantação de rede logística e de formas de produção ligadas à exportação.

Há uma presença histórica da Igreja Católica na região devido ao seu envolvimento na luta por reforma agrária, que contribuiu particularmente para a formação das associações de moradores e para a estruturação das comunidades. Esse protagonismo é mantido na organização das festividades de padroeiros e de outras manifestações culturais. 
A Figura 4 apresenta a consolidação da caracterização genérica das famílias de referências entrevistadas em cada comunidade e de aspectos gerais das comunidades, a fim de permitir a compreensão das configurações espaciais e das tipologias de edificações praticados nas mesmas.

Figura 4 - Caracterização das comunidades estudadas e de uma família

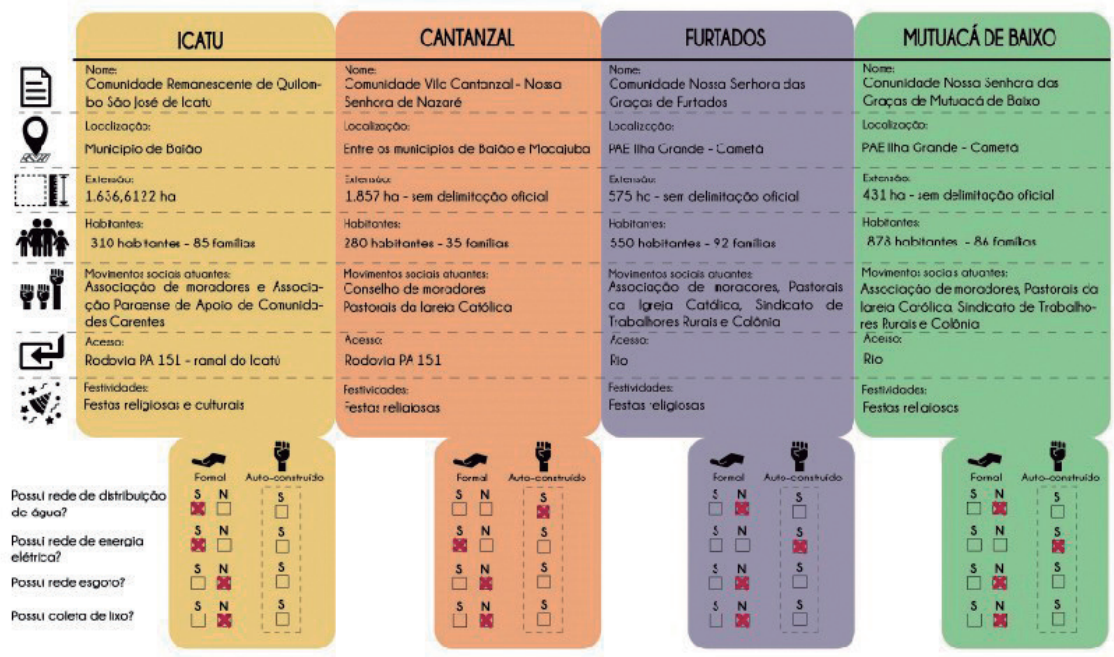

\begin{tabular}{|c|c|c|c|}
\hline FAMILLA-ICATÚ & FAMILIA-CANTANZAL & FAMILIA - FURTADOS & FAMILAA-MUTUACÁ DE BAIXO \\
\hline $\begin{array}{l}\text { Menbirs: } \\
\text { Iou } 5 \text { pesscoss }\end{array}$ & $\begin{array}{l}\text { Nentros } \\
\text { 8pescos }\end{array}$ & $\begin{array}{l}\text { Menbros } \\
6 \text { pessoas }\end{array}$ & $\begin{array}{l}\text { Mentwos: } \\
10 \text { pessoos }\end{array}$ \\
\hline $\begin{array}{l}\text { Sea de produsoo } \\
10 \text { ha }-1 \text { ho (roçcdo) }\end{array}$ & $\begin{array}{l}\text { Aea de rroducas } \\
\text { tha - }(., 5 \text { ha : roçado) }\end{array}$ & $\begin{array}{l}\text { Ano de poducsox } \\
\text { 3ha }\end{array}$ & $\begin{array}{l}\text { Avea ce prodicta } \\
1 \text { hectare }\end{array}$ \\
\hline 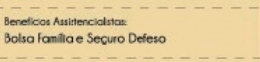 & 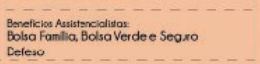 & $\begin{array}{l}\text { Deneficion Asuitienciolistax } \\
\text { Bolsa Fanilia e Seguro Defeso }\end{array}$ & 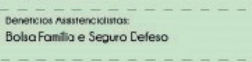 \\
\hline 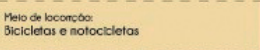 & $\begin{array}{l}\text { Neto de iocomesco } \\
\text { Bicicletas e motocicletas }\end{array}$ & $\begin{array}{l}\text { Meio de loconcica } \\
\text { Rabeta }\end{array}$ & $\begin{array}{l}\text { Meio de loconsoco } \\
\text { Rabeta }\end{array}$ \\
\hline 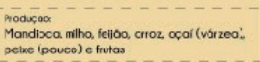 & 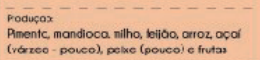 & $\begin{array}{l}\text { PAodursoo } \\
\text { Aca, pexe (pouco), horlapara consuno } \\
\text { oirutas }\end{array}$ & $\begin{array}{l}\text { Próduéós } \\
\text { Aça, peixe (povoo) e hara para o consums }\end{array}$ \\
\hline 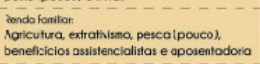 & 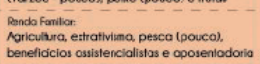 & $\begin{array}{l}\text { Renda Forntilar } \\
\text { Entrativima pesco (poucol, benencicicios } \\
\text { arsistencialistas e aposentodoria }\end{array}$ & 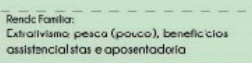 \\
\hline 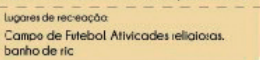 & 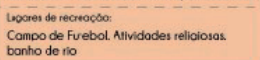 & $\begin{array}{l}\text { lusaren de recreucoso: } \\
\text { Campo de futebol, Alividades reigioscas. } \\
\text { banho de nio }\end{array}$ & 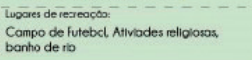 \\
\hline
\end{tabular}

Elaboração das autoras, 2021.

Nesse particular, observou-se que há um condicionamento das condições de moradia e de produção e, por decorrência do modo de vida, pelo tipo de sítio em que a comunidade está localizada, por isso a investigação das comunidades foi organizada a partir da sua localização na terra firme ou várzea. As famílias localizadas em comunidades de terra firme produzem açaí nas várzeas a que têm acesso, nos cursos d'água próximos, apenas para consumo próprio, visto que a quantidade extraída é pequena, diferentemente da condição das comunidades ribeirinhas que têm o extrativismo como atividade econômica principal. 
A redução do tempo de deslocamento aos centros urbanos mais próximos pelo sistema rodoviário enfraqueceu a circulação fluvial e reorientou a prioridade dos serviços e políticas para as estradas. O rio continuou apoiando a produção, mas é a estrada que dá acesso às facilidades do modo de vida urbano. Se antes o centro das comunidades tinha o rio como principal acesso, atualmente os ramais das rodovias estadual e federal assumiram esta função, o que tornou as comunidades ribeirinhas mais segregadas, pela maior distância às rodovias.

As comunidades de terra firme estão estrategicamente localizadas em faixas de terra entre as margens de rios e as estradas, que hoje oferecem acessibilidade mais rápida, e tendem a ter mais diversificação de estratégias de produção. As famílias nas comunidades de terra firme, Icatu e Cantanzal, praticam a agricultura de subsistência, o extrativismo de coleta, caça e pesca artesanal, e comercializam o excedente. Na agricultura, cultivam verduras, e têm a roça de mandioca como cultura principal, em função do grande consumo da farinha na dieta alimentar. Pimenta-do-reino, milho, arroz, feijão e hortaliças compõem o portfólio da agricultura familiar. A exploração dos recursos naturais abrange a coleta da castanha-do-Pará, de outros frutos, do açaí e o manejo da madeira, todos realizados pelas famílias. O açaí encontrado nas comunidades é localizado nas margens de igarapés, e é extraído apenas para consumo próprio.

As famílias nas comunidades de várzea, como em Furtados e Mutuacá de Baixo, quanto às atividades agroextrativistas respeitam os costumes e tradição, e mantêm a força de trabalho familiar. Os moradores do PAE Ilha Grande utilizam áreas de roça e a pesca artesanal para produção de alimentos para subsistência, com o propósito de garantir segurança alimentar, e contam com a extração do açaí como principal atividade econômica. Note-se que a pesca é permitida para a alimentação familiar, bem como para comercialização entre os moradores do assentamento, conforme os critérios adotados nos acordos, e o atendimento à legislação ambiental quanto ao período, à forma e ao equipamento (INCRA, 2007).

A valorização do açaí tem permitido às comunidades de Furtados e Mutuacá de Baixo, mudanças no padrão de consumo de alimentos com substituição do alimento nativo pelo industrializado, e a aquisição de equipamentos que melhoram as suas condições de vida. Os moradores reportam como melhorias na qualidade de vida a compra de televisão, antena parabólica, aparelho de celular, DVD, geladeira, freezers, geradores, motores e outros.

Em todas as entrevistas realizadas com famílias de ambos os tipos de localização da comunidade, foi informado que os benefícios assistenciais do governo federal, como Bolsa Família, Seguro Defeso, Bolsa Verde e outros 
ajudam a compor a renda de cada família. É importante ressaltar que existem membros das famílias que trabalham na cidade ou em outros contextos, onde recebem salários que contribuem para a composição da renda familiar.

Quanto à infraestrutura, houve a implantação do programa "Luz para Todos" pelo governo federal em 2006, que também viabilizou sinal de internet e telefonia por antena externa, com uso restrito a algumas horas do dia. Contudo ainda há casos de comunidades localizadas na várzea não assistidas pelo programa citado que construíram suas próprias redes de distribuição de energia elétrica precárias, com problemas técnicos e clandestinas -, mas que viabilizaram o acesso a essa infraestrutura. Nas comunidades, cada residência conta com uma fossa séptica e um poço artesiano e, quando isso não é possível, os poços são compartilhados entres os vizinhos mais próximos. Além disso, não existe coleta de lixo nas comunidades rurais e a disposição dos resíduos é "resolvida" por sua queima.

Segundo informações obtidas em campo por meio de entrevistas e observação direta, foi possível entender a evolução dos arranjos espaciais no decorrer dos anos. Em todas as comunidades foi explicado que a configuração espacial atual é consequência do crescimento populacional dos últimos anos, por aumento no número de famílias e de pessoas que requerem instalação de infraestrutura, seja por meio de políticas públicas seja de forma clandestina. A Figura 5 apresenta uma representação das transformações espaciais das comunidades de várzea e terra firme.

A estruturação espacial dos assentamentos pesquisados, tanto em área de várzea quanto de terra firme, é composta por três tipos de espaço: o Centro da Comunidade, Áreas de Trabalho e Áreas Residenciais. O Centro de Comunidade é o espaço onde está localizado um conjunto de edificações consideradas essenciais para os moradores: igreja, escola, posto de saúde, pequenos estabelecimentos comerciais, barracão e associação de moradores. Pode haver variações, mas estes são os edifícios mais comumente encontrados, além do principal espaço público: o polivalente campo de futebol. O Centro da Comunidade é o espaço de encontro, de sociabilidade, de serviços, das festividades religiosas e culturais. Não existem muros ou cercas delimitando espaços ou edificações que constituem o Centro, nas comunidades estudadas, o que contribui para um senso de coletividade forte e expressão de identidade espacial. Contudo observa-se uma tendência de concentração de serviços oferecidos pelo poder público no centro da comunidade (ex.: caixa d'água), o que é seguido pela instalação de residências nas suas proximidades, para viabilizar o acesso às infraestruturas. 
Figura 5 - Esquema das transformações na espacialidade dos assentamentos de várzea e terra firme
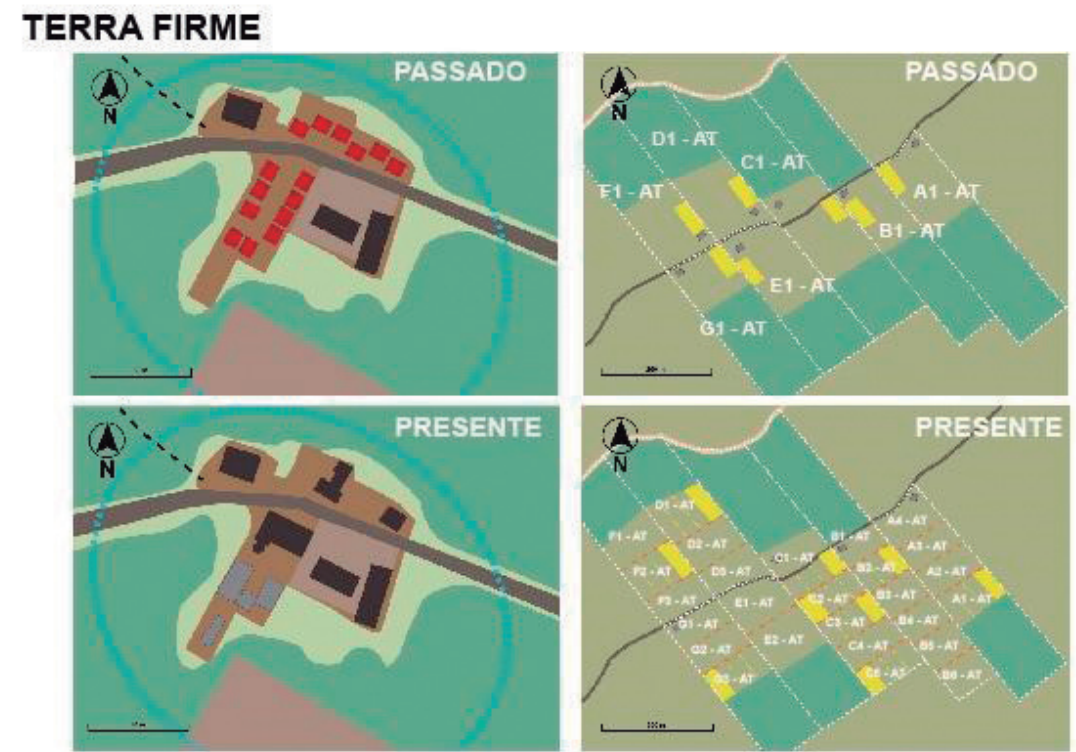

\section{LEGENDA}

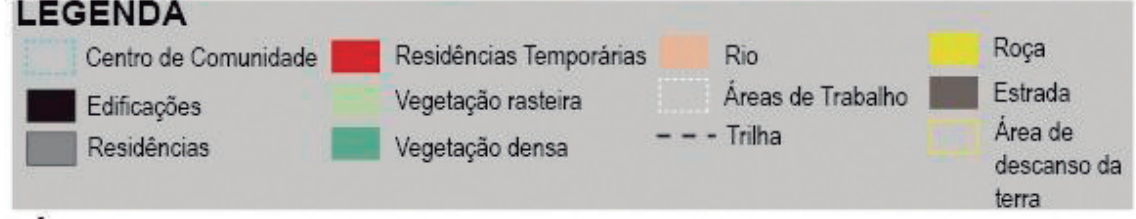

\section{VÁRZEA}
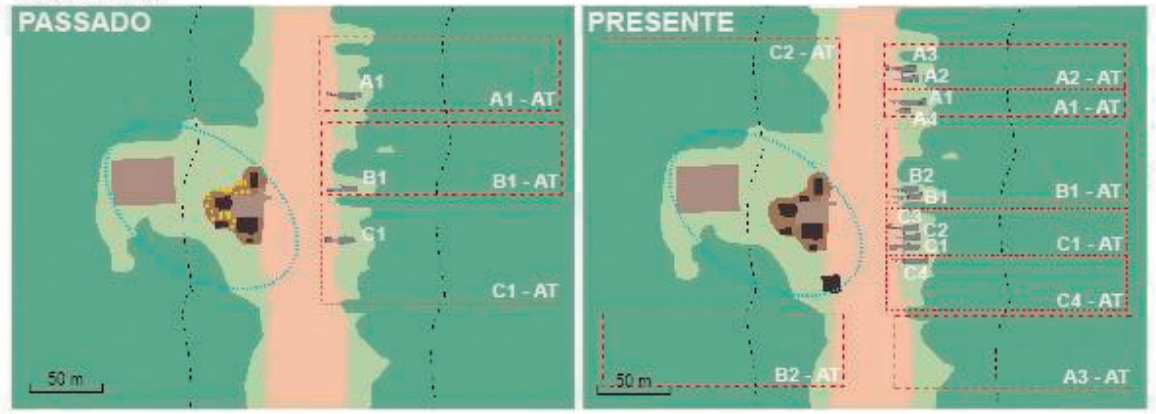

\section{LEGENDA}

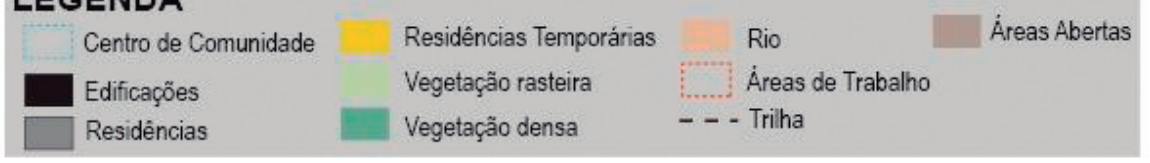

Elaboração das autoras, 2021.

Segundo as entrevistas, em todas as comunidades, independentemente de serem localizadas na várzea ou terra firme, as Áreas de Trabalho são delimitadas 
e individualizadas por família, seguindo os limites acordados entre os moradores da comunidade, para garantir que cada família possa obter o seu sustento por meio do trabalho na terra.

Verificou-se também que a sucessão da terra dentro das famílias estudadas não segue um padrão, como ocorre em outras regiões do Brasil. Estas observações confirmam o que as pesquisas no campo da antropologia, realizadas por Stoll e Medaets (2020), Neves (2009) e Araújo e Schiavoni (2002), informam sobre a não existência de uma regra definida para a transferência de porções de terra como herança na Amazônia. Além da herança, é comum a prática de compra e venda de terras entre pessoas de uma mesma comunidade ou de comunidades diferentes.

Porém, em relação ao acesso à política de crédito, o produtor tem que definir se deseja recursos para custeio ou investimento. Os valores de custeio são destinados à compra de insumos e demais itens para atividade normal da produção - agrícola ou pecuária. Essas operações exigem documentos que variam conforme o estado, o tipo de lavoura e as peculiaridades produtivas de cada região. Em sua maioria são necessários: Declaração de Aptidão ao Programa Nacional de Fortalecimento da Agricultura Familiar (Pronaf); Mapa de Localização da Lavoura Financiada; Licenciamento ambiental, se houver necessidade; Certidão Negativa de Débito junto ao Instituto Nacional do Seguro Social (INSS); e Certificado de Cadastro de Imóvel Rural (CCIR) emitido pelo Instituto Nacional de Colonização e Reforma Agrária (Incra), que comprova o cadastro como imóvel rural (SAIBA..., 2015).

Esse último documento exige que seja informado o Cadastro de Pessoa Física (CPF) do declarante, o que tem fomentado um processo de individualização da terra por herdeiro e gerado parcelas com dimensões incompatíveis com as formas de manejo necessárias para um volume de produção capaz de garantir sustento na região. Como o crédito também é fator fundamental para a produção e sustento do núcleo familiar, observa-se que os procedimentos burocráticos da gestão pública são incentivadores da reorganização espacial da área de trabalho das comunidades.

Na várzea, as Áreas de Trabalho são manejadas em sua totalidade devido à necessidade de grande extensão de terra para viabilizar o extrativismo do açaí. Devido à alta incidência natural do açaízeiro na região tocantina, as áreas de produção se constituem em agroflorestas (os açaizais) que recebem diferentes estratégias de manejo e contam com plantação de outras espécies para controlar a sombra dos açaizeiros. Todavia estudos recentes apontam transformações no cenário de manejo dos açaizais e indicam a tendência de prática de monocultivo do açaí para aumento do volume de produção, bem como para atendimento das 
demandas do mercado (ARAÚJO; NAVEGANTES-ALVES, 2015; POMPEU et al., 2021 TAGORE; MONTEIRO; CANTO, 2019), o que significa risco de desenvolvimento de pragas ou de desequilíbrio ecossistêmico para um produto que é muito importante para a alimentação das comunidades da região.

Nas comunidades localizadas na terra firme, as Áreas de Trabalho não são usadas em sua totalidade, apenas uma parte é reservada para o roçado a cada vez. Esse sistema de cultivo de agricultura de subsistência, relatado nas entrevistas, é bastante comum na região e enquadra-se no manejo de corte e queima da floresta primária ou secundária. A formação de roças depende da alternação dos períodos de cultivo e de pousio, quando a vegetação secundária (capoeira) cresce e depois de algum tempo é transformada em fertilizante para o próximo período de plantação (KATO et al., 2014; OLIVEIRA et al., 2007). Pelo que foi observado nas comunidades estudadas, a forma de organização da produção somada à extensão da área das comunidades tem impedido uma transição das práticas de produção familiar para o monocultivo do açaí, o que as torna menos vulneráveis quanto à segurança alimentar que as comunidades de várzea.

Segundo relatos, há 30 anos nos assentamentos de várzea, as residências eram mais distantes uma das outras, o espaço de trabalho (área para agricultura, extrativismo e outras atividades) também era ambiente de residência de apenas um núcleo familiar (representando na Figura 5 como A1, B1, C1). Hoje com o processo de crescimento populacional nas comunidades, às margens do espaço de trabalho da família A1 foram cedidas para construção das residências dos desmembramentos da família A, representados como famílias A2 e A3. Esses núcleos familiares mais recentes, A2 e A3, apresentam Áreas de Trabalho mais distantes que, para serem alcançadas, demandam meios de transporte como barcos e rabetas.

A Figura 5 apresenta as mudanças espaciais ocorridas no decorrer de 30 anos nos assentamentos de terra firme. Os depoimentos das famílias informaram que antigamente as residências temporárias eram construídas nas proximidades do Centro de Comunidade, para apoiar os períodos das festividades religiosas, enquanto as residências fixas ficavam nas Áreas de Trabalho, o local dos cultivos para a subsistência e produção de farinha. Com o passar dos anos, as residências temporárias do centro das comunidades tornaram-se fixas devido às melhorias de infraestruturas realizadas nas comunidades estudadas, tais como rede de distribuição de água e de rede de energia elétrica.

É digno de nota que os centros de comunidade são tão antigos quanto as próprias comunidades tradicionais, mas foram reproduzidos na comunidade Cantanzal, e uma justificativa é dada por Lima (2005), que explica que os movimentos sindicais e entidades religiosas promoveram um esforço de 
aglutinação de agricultores dispersos por meio de áreas comunitárias doadas, fenômeno que reforça a potência da espacialidade tradicional. Contudo, conforme ocorre o aumento populacional das comunidades, observa-se uma nova transição em curso nos centros das comunidades, com estabelecimento das moradias permanentes, e nas áreas de produção, com a subdivisão da terra, para acomodação das necessidades de um novo núcleo familiar, embora exista um limite do ecossistema para o aumento da produção em áreas manejadas.

A organização familiar é o ponto principal para a estruturação do trabalho e para o entendimento da organização da Área de Trabalho de ambos os tipos de assentamento. Por outro lado, a construção de repertórios espaciais a partir da compreensão dos processos de reorganização das comunidades é passo fundamental para a concepção de todas as políticas públicas que interferem no ordenamento territorial (desde a produção da moradia até a concessão do crédito para o pequeno produtor), para torná-las mais adequadas às práticas testadas, e que são historicamente exitosas, no contexto amazônico.

\section{CONCLUSÕES}

As políticas desenvolvimentistas desencadearam um processo de urbanização extensiva na Amazônia que extrapolou as cidades e impactou todo o território. Nessa perspectiva, esta pesquisa investigou atributos da ocupação amazônica em assentamentos humanos rurais - de várzea e terra firme - que desenvolveram uma relação de interdependência com as cidades mais próximas, em busca de matrizes espaciais para a compreensão da interdependência entre comunidades e recursos naturais na Amazônia. Compreender essa interdependência é importante porque ela existe, com níveis diferentes de caracterização, em assentamentos isolados, nos espaços periurbanos das grandes cidades da região - onde foram constituídos assentamentos rurais especiais, motivados por migração de grupos tradicionais, ou no processo de assimilação das comunidades por ocasião da expansão das cidades próximas.

À luz do entendimento do espaço social (espaço concebido, percebido e vivido) e com o auxílio da caracterização do modo de vida de cada comunidade estudada, foi possível destacar a necessidade de articulação entre as escalas do território, visto que os arranjos espaciais entre cidade e assentamentos tradicionais rurais são crescentemente complementares.

As comunidades estudadas são portadoras de qualidades de vida valorizadas por seus habitantes. Suas práticas produtivas garantem o fornecimento de alimentos para a cidade, a subsistência e a identidade cultural de suas populações, 
além de conservarem a biodiversidade. Contudo os arranjos espaciais diferem entre os assentamentos de várzea e de terra firme, mesmo igualmente afetados pelo processo de adensamento populacional das comunidades.

Os assentamentos de comunidades de várzea e terra firme apresentam modos de vida com expressões espaciais distintas, mas, em ambos os casos, o centro da comunidade é o ambiente da coletividade e atendem ao interesse coletivo, sem áreas delimitadas - abrigam as atividades de serviços, recreativas, ambientes de reunião e de sociabilidade. A delimitação e a individualização da terra existem somente nas Áreas de Trabalho.

Observou-se que no Baixo Tocantins a reorganização do espaço das comunidades é resultado: de adensamento populacional, aumento no número de famílias, instalação de infraestrutura (seja por ação de políticas públicas ou de maneira clandestina), e da própria assimilação de expectativas de consumo e de acesso a serviços das populações rurais, inspirados na vida citadina, indicando um duplo sentido da urbanização extensiva na região.

Há uma reorganização em curso nas áreas de várzea, manifesta na separação entre Área de Trabalho e Áreas de Residência, busca por novas Áreas de Trabalho e aproximação das Áreas de Residência ao Centro de Comunidade. Na terra firme, a Área de Trabalho sofre com o processo de subdivisão para viabilizar espaço de cultivo para cada núcleo familiar, sem padrão definido.

As transformações diretas e indiretas, provocadas por políticas públicas, não são sensíveis às formas de apropriação do território, nem ao modo de vida das comunidades. As políticas promoveram ações homogeneizantes, isso porque são baseadas na lógica citadina, impondo costumes, construções e alterações nas formas de manejo para atender às novas demandas dos grandes mercados urbanos. A assimilação da vida urbana tem desvalorizado padrões alimentares e ameaçado valores, costumes e heranças que constituíram um saber (cultura) desenvolvido por gerações nas comunidades.

A procura de melhoria nas condições de produção e reprodução da vida, de acesso a políticas públicas, serviços e infraestrutura, vem acontecendo sem a compreensão do custo imposto pelo improviso e pela ação incremental. Nessa perspectiva, o artigo buscou advertir sobre a necessidade de alargar a investigação interdisciplinar e multiescalar nesses espaços, iluminando especificidades que decorrem dos limites do bioma, e o hibridismo resultante da formação histórica da região. As comunidades podem ser interpretadas como pequenas vilas individualmente, mas se revelam como entidades interarticuladas entre si, com a natureza e com as cidades, que necessitam de políticas públicas que considerem a complexidade dessas relações e que reconheçam sua importância socioambiental. 


\section{AGRADECIMENTOS}

Ao CNPQ, pelo financiamento à pesquisa por meio dos processos 307537/2018-8 e 430801/2016-5, à Capes pela bolsa de mestrado, e ao trabalho do(a) parecerista.

\section{REFERÊNCIAS}

ALMEIDA, A. W. B. Terras tradicionalmente ocupadas. Revista Brasileira de Estudos Urbanos e Regionais, São Paulo, v. 6, n. 13, p. 09-32, 2004.

ARAÚJO, C. T. D.; NAVEGANTES-ALVES, L. F. Do extrativismo ao cultivo intensivo do açaizeiro (Euterpe oleracea Mart.) no estuário amazônico: sistema de manejo e suas implicações sobre a diversidade de espécies arbóreas. Revista Brasileira de Agroecologia, Curitiba, v. 10, n. 1, p. 12-23, 2015.

ARAÚJO, R.; SCHIAVONI, G. A ilusão genealógica: parentesco e localidade na fronteira agrária da Amazônia. Agricultura Familiar: pesquisa, formação e desenvolvimento, Belém, v. 01, n. 03, p. 15-39, 2002.

BECKER, B. A urbe amazônida: a floresta e a cidade. Rio de Janeiro: Garamond, 2013.

BRASIL. Decreto $\mathbf{N}^{\mathbf{0}} \mathbf{6 . 0 4 0}$, de 07 de fevereiro de 2007. Institui a Política Nacional de Desenvolvimento Sustentável dos Povos e Comunidades Tradicionais. Brasília, DF: Presidência da República, [2007]. Disponível em: http://www.planalto.gov.br/ccivil_03/_ato2007-2010/2007/decreto/d6040. htm. Acesso em: 14 dez. 2021.

BRENNER, N. Implosions/explosions: towards a study of planetary urbanization. Berlin: Jovis, 2013.

BRITO, D. C. Modernização de superfície: Estado e desenvolvimento na Amazônia. Belém: NAEA/UFPA, 2001.

CARDOSO, A. C. D.; LIMA, J. J. F. Tipologias e padrões de ocupação na Amazônia Oriental. In: CARDOSO, A. C. D. (Ed.). O urbano e o rural na Amazônia. Belém: EDUFPA, 2006. p. 55-110.

CARDOSO, A. C. D.; CANDIDO, L. S.; MELO, A. C. C. Canaã dos Carajás: um laboratório sobre as circunstâncias da urbanização, na periferia global e no alvorecer do século XXI. Revista Brasileira de Estudos Urbanos e Regionais, São Paulo, v. 20, n. 1, p. 121-140, 2018.

CASTRO, E. Território, biodiversidade e saberes de populações tradicionais. Papers do NAEA, Belém, n. 92, p. 1-16, 1998. 
CORRÊEA, R. B. A produção do açaí na Amazônia tocantina: perspectiva para o desenvolvimento regional. In: ENCONTRO NACIONAL DE GEÓGRAFOS, 18., 2016, São Luís. Anais [...]. São Luís: ENG-UFMA, 2016. p. 1-12.

COSTA, G. S. Desenvolvimento rural sustentável com base no paradigma da agroecologia. Belém: NAEA/UFPA, 2006.

COSTA, S. A. P.; GIMMLER NETTTO, M. M. Fundamentos de morfologia urbana. Belo Horizonte: C/Arte, 2015.

DURKHEIM, E. Da divisão do trabalho social. São Paulo: WMF Martins Fontes, 2010.

GOMES, T. V.; CARDOSO, A. C. D.; OLIVEIRA, K.; COELHO, H.

Santarém (PA): um caso de espaço metropolitano sob múltiplas determinações. Cadernos Metrópole, São Paulo, v. 19, p. 891-918, 2017.

GUERRA, I. Modos de vida: novos percursos e novos conceitos. Sociologia, Porto Alegre, n. 3, p. 59-74, 1993.

HÉBETTE, J.; MOREIRA, E. S. Situação social das áreas rurais amazônicas. Cad. Est. Soe., Recife, v. 12, n. 2, p. 383-406, 1996.

IBGE. Censo demográfico 2010. Instituto Brasileiro de Geografia e Estatística, Rio de Janeiro, 2010. Disponível em: http://www.ibge.gov.br/ home/estatistica/populacao/cnso2010/default_populacao.shtm. Acesso em: 02 maio 2019.

IBGE. Cidades. Instituto Brasileiro de Geografia e Estatística, Rio de Janeiro, 2016. Disponível em: http://www.ibge.gov.br. Acesso em: 21 ago. 2018.

INCRA. Plano de Utilização para o Projeto Agroextrativista Ilha Grande Cametá. Cametá: PAE/INCRA/EMBRAPA/STTR, 2007.

IPEA. Região de Integração Tocantins-PA: um novo olhar sobre o extrativismo e alguns aspectos socioeconômicos. Rio de Janeiro: IPEA, 2011. KATO, O. R.; VASCONCELOS, S. S.; FIGUEIREDO, R. O.; CARVALHO, C. J. R.; SÁ, T. D. A.; SHIMIZU, M. K. Agricultura sem queima: uma proposta de recuperação de áreas degradadas com sistemas agroflorestais sequenciais. In: LEITE, L. F. C.; MACIEL, G. A.; ARAÚJO, A. S. F. (ed.). Agricultura conservacionista no Brasil. Brasília, DF: Embrapa, 2014. p. 189-216.

LEFEBVRE, H. A revolução urbana. Belo Horizonte: Editora da UFMG, 1999.

LEFEBVRE, H. A produção do espaço. Trad. Doralice Barros Pereira e Sérgio Martins. Belo Horizonte: [s. n.], 2006. 
LIMA, D. Diversidade socioambiental nas várzeas dos rios Amazonas e Solimões: perspectivas para o desenvolvimento da sustentabilidade. Manaus: Ibama/ProVárzea, 2005.

LOPES, R. J. 1499: A pré-história do Brasil. 1. ed. Rio de Janeiro: Harper Collins, 2017

MALHEIRO, B. C. P.; TRINDADE JÚNIOR, S-C. C. Entre rios, rodovias e grandes projetos: mudanças e permanências em realidades urbanas do Baixo Tocantins (Pará). História Revista, Goiânia, v. 14, p. 1-30, 2009.

MENEZES NETO, A. J. A Igreja Católica e os movimentos sociais do campo: a Teologia da Libertação e o Movimento dos Trabalhadores Rurais sem Terra. Caderno CRH, Salvador, v. 20, n. 50, p. 331-341, 2007.

MDA. Plano Territorial de Desenvolvimento Rural Sustentável do Baixo Tocantins (PTDRS - Baixo Tocantins). Belém: Secretária de Desenvolvimento Territorial/Ministério do Desenvolvimento Agrário, 2011. MONTE-MÓR, R. L. Urbanização extensiva e lógicas de povoamento: um olhar ambiental. In: SANTOS, M.; SOUZA, M. A. A.; SILVEIRA, M. L. (org.). Território: globalização e fragmentação. São Paulo: Hucitec/Anpur, 1994. p. 169-181.

MONTE-MÓR, R. Urbanização, sustentabilidade, desenvolvimento: complexidades e diversidades contemporâneas na produção do espaço urbano. In: COSTA, G.; COSTA, H.; MONTE-MÓR, R. (org.). Teorias e práticas urbanas: condições para a sociedade urbana. 11. ed. Belo Horizonte: C/Arte, 2015. p. 55-70.

NEVES, D. P. (org.). Processos de constituição e reprodução do campesinato no Brasil: formas dirigidas de constituição do campesinato. São Paulo: Editora UNESP; Brasília, DF: Núcleo de Estudos Agrários e Desenvolvimento Rural, 2009.

OLIVEIRA, J. S. R.; KATO, O. R.; OLIVEIRA, T. F.; QUEIRÓZ, J.; CARDOSO, R. Agricultura familiar e SAFs: produção com conservação na Amazônia Oriental, nordeste paraense. In: CONGRESSO BRASILEIRO DE SISTEMAS DE PRODUÇÃO, 7., 2007, Fortaleza. Anais [...]. Fortaleza: Embrapa Agroindústria Tropical, 2007. Não paginado.

OLIVEIRA, K. D. Entre a várzea e a terra firme: estudo de espaços de assentamentos tradicionais urbano rurais na região do Baixo Tocantins. 2020. Dissertação (Mestrado em Arquitetura e Urbanismo) - Programa de Pós-Graduação em Arquitetura e Urbanismo, Universidade Federal do Pará, Belém, 2020. 
OLIVEIRA NEVES, L. J. Amazônia, um espaço diversificado.

Revista de História da Biblioteca Nacional, Rio de Janeiro, n. 44, p. 38, maio 2009. Disponível em: http://revistadehistoria.com.br/v2/ home/?go=detalhe\&id=2376. Acesso em 15 dez. 2021.

PINHO, G. F.; OLIVEIRA, K. D.; CARDOSO, A. C. D. Entre o vernacular e o técnico - análise da forma de vilas rurais na Região Tocantina. Revista de Geografia e Ordenamento do Território, Porto, n. 22, p. 81-108, dez. 2021. POMPEU, G. S. S.; SANTOS, V. P. S.; PINTO, E. S.; RODRIGUES, R. P. Manejo de agroflorestas na Amazônia Tocantina: Percepções de famílias agricultoras para a educação agroflorestal. Revista Brasileira de Agroecologia, Curitiba, v. 16. n. 1. p. 40-52, 2021.

PONTES, L. Cidade, desenho e natureza: uma reflexão sobre os espaços livres em Marabá. 2015. Dissertação (Mestrado em Arquitetura e Urbanismo) - Programa de Pós-Graduação em Arquitetura e Urbanismo, Universidade Federal do Pará, Belém, 2015.

PORTO-GONÇALVES, C.W. Amazônia, amazônias. 2. ed. São Paulo: Contexto, 2005.

SAIBA quais são os documentos necessários para acessar o Pronaf. Canal Rural, São Paulo, 29 jul. 2015. Disponível em: https://www.canalrural. com.br/multimidia/saiba-quais-sao-documentos-necessarios-para-acessarpronaf-60271/. Acesso: 27 abr. 2020.

STOLL, E. ; MEDAETS, C. Faire sa place et faire « famille» dans les villages de Basse Amazonie (Bresil). Role de la socialisation enfantine dans les dynamiques familiales de transmission. AnthropoChildren: perspectives ethnographiques sur les enfants \& l'enfance, [s. l.], n. 9, p. 1-21, 2020. Disponível em: https://popups. uliege.be/2034-8517/index.php?id=3319\&file=1. Acesso em: 14 dez. 2021.

TAGORE, M. P. B.; MONTEIRO, M. A.; CANTO, O. A cadeia produtiva do açaí: estudo de caso sobre tipos de manejo e custos de produção em projetos de assentamentos agroextrativistas em Abaetetuba, Pará. Amazônia, Organização e Sustentabilidade, Belém, v. 8, n. 2, p. 99-112, 2019. VIANA, A. L. N.; SIMÕES, A. V.; BASTOS, R. Z. Saberes e inovações ribeirinhos, do cacau das várzeas no território do Baixo Tocantins. In: COLÓQUIO ORGANIZAÇÕES, DESENVOLVIMENTO E SUSTENTABILIDADE, 10., 2019, Belém. Anais [...]. Belém: CODS/ UNAMA, 2019. p. 1-16.

WEBER, M. Economia e sociedade: fundamentos da sociologia compreensiva. Brasília, DF: Editora Universidade de Brasília, 1991.

Texto submetido à Revista em 04.01.2021

Aceito para publicação em 07.12.2021 